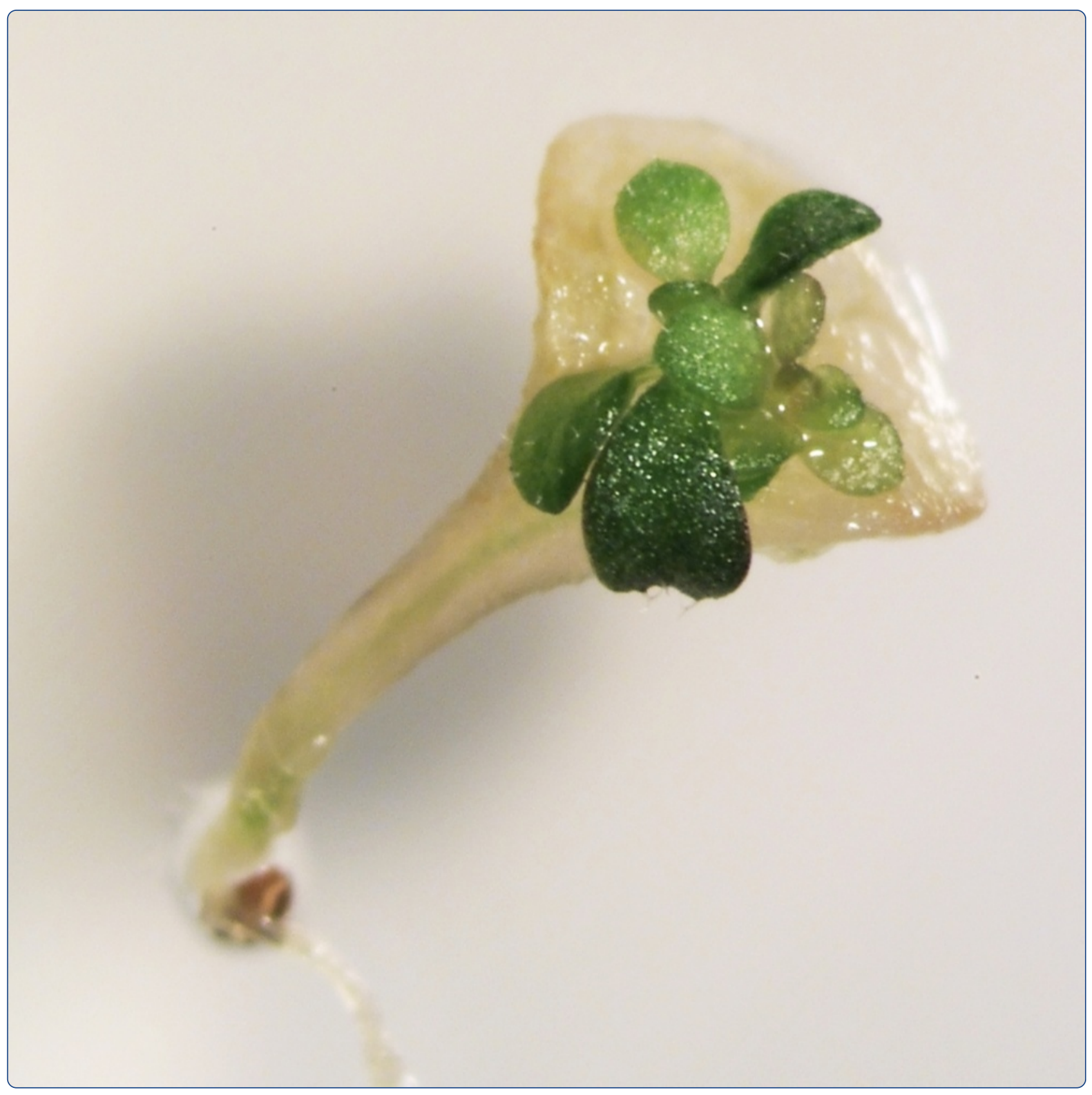

Ectopic shoot meristem generation in monocotyledonous rpk1 mutants is linked to SAM loss and altered seedling morphology

Fiesselmann et al. 


\title{
Ectopic shoot meristem generation in monocotyledonous rpk1 mutants is linked to SAM loss and altered seedling morphology
}

\author{
Birgit S. Fiesselmann ${ }^{1}$, Miriam Luichtl ${ }^{1}$, Xiaomeng Yang ${ }^{1}$, Michaela Matthes ${ }^{1,2}$, Ottilie Peis ${ }^{1}$ \\ and Ramon A. Torres-Ruiz ${ }^{1 *}$
}

\begin{abstract}
Background: In dicot Arabidopsis thaliana embryos two cotyledons develop largely autonomously from the shoot apical meristem (SAM). Recessive mutations in the Arabidopsis receptor-like kinase RPK1 lead to monocotyledonous seedlings, with low (10\%) penetrance due to complex functional redundancy. In strong rpk1 alleles, about $10 \%$ of these (i. e. $1 \%$ of all homozygotes) did not develop a SAM. We wondered whether RPK1 might also control SAM gene expression and SAM generation in addition to its known stochastic impact on cell division and PINFORMED1 (PIN1) polarity in the epidermis.

Results: SAM-less seedlings developed a simple morphology with a straight and continuous hypocotyl-cotyledon structure lacking a recognizable epicotyl. According to rpk1's auxin-related PIN1 defect, the seedlings displayed defects in the vascular tissue. Surprisingly, SAM-less seedlings variably expressed essential SAM specific genes along the hypocotyl-cotyledon structure up into the cotyledon lamina. Few were even capable of developing an ectopic shoot meristem (eSM) on top of the cotyledon.

Conclusions: The results highlight the developmental autonomy of the SAM vs. cotyledons and suggest that the primary rpk1 defect does not lie in the seedling's ability to express SAM genes or to develop a shoot meristem. Rather, rpk1's known defects in cell division and auxin homeostasis, by disturbed PIN1 polarity, impact on SAM and organ generation. In early embryo stages this failure generates a simplified monocotyledonous morphology. Once generated, this likely entails a loss of positional information that in turn affects the spatiotemporal development of the SAM. SAM-bearing and SAM-less monocotyledonous phenotypes show morphological similarities either to real monocots or to dicot species, which only develop one cotyledon. The specific cotyledon defect in rpk1 mutants thus sheds light upon the developmental implications of the transition from two cotyledons to one.
\end{abstract}

Keywords: RPK1, Arabidopsis, Shoot meristem, SAM, Cotyledon, Monocot, Dicot, Plant embryo, Angiosperm evolution

\section{Background}

As typical representatives of dicot angiosperms, Arabidopsis thaliana seedlings display a body plan beginning with an epicotyl region harbouring the shoot apical meristem (SAM), flanked by two cotyledons and followed by the hypocotyl, which ends in a root tip carrying the root apical meristem (RAM) [1]. The initiation of cotyledons vs.

\footnotetext{
* Correspondence: Ramon.Torres@wzw.tum.de

'Lehrstuhl für Genetik, Technische Universität München,

Wissenschaftszentrum Weihenstephan, Emil-Ramann-Str. 8, D-85354 Freising, Germany

Full list of author information is available at the end of the article
}

SAM is largely independent, as evidenced by mutations that delete the SAM but not the cotyledons $[2,3]$ and vice versa $[4,5]$.

Although exceptions from normal cotyledon number in angiosperms are known in several genera [6] cotyledon number is a relatively constant pattern element. Modern taxonomy recognizes eudicots with two cotyledons and monocots with one cotyledon, as monophyletic groups [7, 8]. However, the mechanisms of "counting"and arranging these organs together with the SAM in order to establish the apical region are poorly understood.

\section{Ciomed Central}


The use of Arabidopsis thaliana mutants with cotyledon defects helps to get a deeper insight into this developmental process. Careful categorization of known mutants displaying cotyledon defects reveals a group, which obviously reflects more fundamental perturbations such as cell differentiation in altered meristem program [9, 10], control of meristem cell fate and lateral organ development in dornröschen [11] and division plane orientation in fass [12]. This leaves a number of seedling mutants whose defects are cotyledon specific. These mutants are regularly linked to defects in auxin synthesis and transport by the polar auxin efflux carrier PIN1, which generates auxin maxima required to induce cotyledon primordia $[13,14]$. For instance, mutants of the AGC kinase PINOID (PID) and Dmyo-inositol-3-phosphate synthase (MIPS) frequently produce abnormal supernumerary cotyledon numbers $[15$, 16] whereas combinations of pinoid (pid) with mutants of related kinases, auxin-synthesis genes and the NPH3-like gene ENHANCER OF PINOID (ENP/enp) result in cotyledon-less seedlings which retain a functional SAM [4, 5, 17-19]. In contrast, mutants specifically segregating a monocotyledonous phenotype are relatively rare and known from sic mutants in pea and mutations in the Arabidopsis receptor-like kinase $R P K 1$ [20, 21]. The reason for this sparsity is possibly due to redundant gene functions encoded in the Arabidopsis genome. In fact, the monocotyledonous phenotype of $r p k 1$ mutants has a maximum penetrance of ca. $10 \%[21,22]$, which could be elevated by adding mutations in the related TOAD2/RPK 2 . However, this combination simultaneously resulted in additional severe pattern effects and high frequency of embryo lethality because TOAD2/RPK2 has adopted additional functions in radial pattern formation $[21,23]$ and as regulator of meristem development [24].

Avoiding such pleiotropic effects $r p k 1-7$ and $r p k 1-6$ single mutants were recently analysed. This revealed that the primary $r p k 1$ defect stochastically compromises epidermal cell division and PIN1 polarity during embryogenesis [22]. The defect is stochastic because the accuracy of every new cell division depends on whether the redundant $R P K 1$-like genes achieve the required threshold of RPK1 function or not. This implies that the rpk1 defect can become manifest in different stages (time dependence) and in different regions (spatial dependence). The perturbation of epidermal cell division and PIN1 polarity in a cotyledon anlage might disturb or eliminate the establishment of an auxin maximum and lead to monocotyledonous seedlings (henceforth named monocot seedlings for convenience). The existence of SAM-less monocot seedlings suggested an interference with both cotyledon and SAM development during the early globular stage in the strong $r p k 1$ alleles.

Here we show that SAM-less monocot seedlings retain basic SAM functions. However, they develop a simple morphology with a continuous hypocotylcotyledon organization that lacks a clear separation between these structures. The well-developed lamina is sometimes larger than in the wild-type. Although these monocot seedlings have initially no SAM, they have not lost the capacity to generate one. Some develop a delayed SAM or even an ectopic shoot meristem (eSM) on the adaxial side of the cotyledon. Our analyses suggest that the topological peculiarity of these monocot seedlings is linked to the loss of a spatially and timely coordinated expression of SAM specific genes during early embryogenesis, indicating a loss of positional information by altered morphology.

\section{Results}

Strong rpk1 alleles generate SAM-less monocot seedlings The allele rpk1-7 was induced in a gl1 Columbia background and generates ca. $10 \%$ seedlings with cotyledon abnormalities most of them lacking one cotyledon [22]. We detected that, five days after germination, some of the monocot seedlings did not possess developed SAMs in comparison to their monocot siblings (Fig. 1a-c). The cotyledon of these seedlings varied in shape and size and had a well-developed lamina with recognizable adaxial and abaxial sides (Fig. 1). The SAM-less monocots regularly occurred in the pedigree of crosses with plants of different genetic backgrounds with a frequency ranging between $0.5 \%$ and $1.8 \%$ of all seedlings (Table 1 ). Upon further growing, part of the SAM-less seedlings developed SAMs at some distance from the cotyledon lamina, suggesting that meristem development lagged behind that of SAM-bearing monocots. We considered that the SAM-less phenotype could be a specific character of the rpk1-7 allele, which is a fast neutron-induced inversion [22]. Therefore, we searched this phenotype in the independently generated rpk1-6 allele, which is a T-DNA insertion in the RPK1 coding region [22] and found SAM-less seedlings with similar frequencies as in $r p k 1-7$ (Table 1). The other SAM-less seedlings did never develop a normal SAM but necrotic cotyledons and green, continuously growing roots as long as cultured in sterile 1/2MS medium (Fig. 1d). Notably, in these seedlings the hypocotyl and cotyledon petiole formed a continuous structure without recognizable separation of a SAM region (Fig. 1c, e and $\mathrm{f}$ ). This was true for both alleles (compare Fig. 1c, e, g) and showed that cell differentiation in these tissues had been fundamentally altered. Whole mount preparations of $r p k 1-7$ seedlings displayed vascular defects stressing RPK1's link to PIN1 polarity and auxin transport [22]. In $r p k 1$ monocots, the wildtype diarchic vascular system, which branches into both cotyledons, was variably organized. Either both strands intruded into the remaining cotyledon, or one strand ended in the "hypocotyl". In other cases supernumerary 

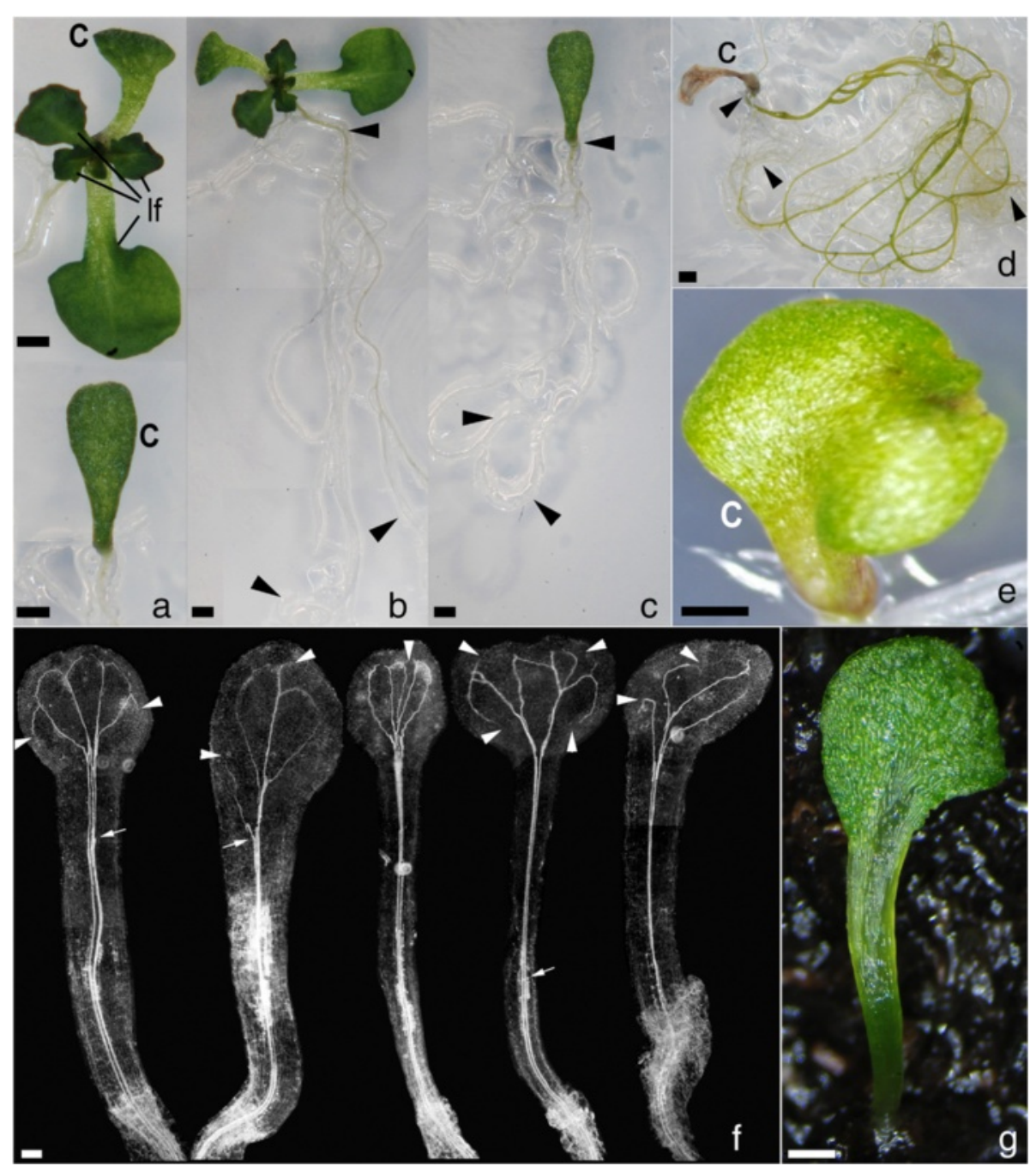

Fig. 1 Morphology in SAM-less rpk1 monocot seedlings. a Magnifications of parts of monocot rpk $1-7$ seedlings (g/1/g/1 background) with SAM and primary leaves (top) and without SAM (bottom). b and $\mathbf{c}$ Whole plants with long roots (indicated by arrowheads) illustrate the continuous root growth. d A shoot-less monocot seedling from long-term cultivation shows a necrotic cotyledon while the root has continued growth and turned green. e A SAM-less monocot seedling with a homozygous rpk1-7 GL1 background (carrying a PIN1:GFP reporter). f Seedlings cleared with Hoyers mount visualize the vascular system in the contiguous hypocotyl-cotyledon structure with interruptions (white arrowheads) and supernumerary and/or blindly terminating vascular elements (small arrows). There is no bend recognizable, which in the wild-type separates apically the SAM/epicotyl from the laterally placed cotyledon. $\mathbf{g}$ A SAM-less monocot seedling originating from the rpk $1-6$ allele. Cotyledons (c), normal leaf (If) indicated. Scale bars: $1 \mathrm{~mm}$ a-e, $0.5 \mathrm{~mm} \mathbf{g}, 100 \mu \mathrm{M} \mathbf{f}$

vascular cell files were formed (Fig. 1f; Additional file 1: Figure S1).

\section{SAM-less monocot seedlings are capable of developing ectopic meristems on the cotyledon}

During the analyses of $r p k 1-7$ monocots we repeatedly found SAM-less seedlings, which could enter another rare developmental route by developing an eSM on the adaxial surface of the cotyledon (Fig. 2). The eSMs did not develop on any other SAM-bearing dicot or monocot rpk1 seedling and displayed some specific characteristics. Firstly, the eSM was positioned on the recognizable adaxial not on the abaxial site of the cotyledon (Fig. 2a-e). Secondly, the eSM appeared in median position on the cotyledon i. e. near the mid-rip (Fig. 2a, b, e1-e5). Thirdly, the eSM generated primary leaves with irregular phyllotactic patterns not additional cotyledons (Fig. 2a, b). Primary leaves of the original line carrying the glabra1 mutation did not form the trichomes. However, back-crossing to GLABRA1 background (Table 1) demonstrated that these developed the leaf specific trichomes (Fig. 2c, d). The eSMs generated single leaf organs or (in the other extreme) even rosettes with fertile shoots (Fig. 2e6). The resulting pedigree exhibited a similar range of cotyledon 
Table 1 Frequency of rpk 1-7 monocot plants without SAM

\begin{tabular}{|c|c|c|c|c|c|c|c|c|}
\hline \multirow[t]{2}{*}{ RPK1 mutant line } & \multicolumn{2}{|c|}{ Wild-types (dicot. rpk1-x) } & \multicolumn{2}{|c|}{ Anisocot./other irregular cots } & \multicolumn{2}{|c|}{ Monocots + SAM } & \multirow{2}{*}{$\begin{array}{l}\text { Monocots -SAM } \\
{\left[\%^{\mathrm{b}}\right]}\end{array}$} & \multirow[t]{2}{*}{ Back-ground } \\
\hline & + Trich. $^{a}$ & -Trich. & + Trich. & -Trich. & +Trich. & -Trich. & & \\
\hline \multicolumn{9}{|l|}{ rpk1-7 allele: } \\
\hline$F N^{9-3}-1$ & - & 69 & - & 1 & - & 9 & 1 [1.3\%] & $g / 1 / g / 1$ \\
\hline $\mathrm{FN}^{9-3}-2$ & - & 290 & - & 15 & - & 20 & $6[1.8 \%]$ & $g / 1 / g / 1$ \\
\hline $\mathrm{FN}^{9-3}{ }_{-3}$ & - & 281 & - & 12 & - & 23 & $2[0.6 \%]$ & $g / 1 / g / 1$ \\
\hline $\mathrm{FN}^{9-3}-4$ & - & 169 & - & 10 & - & 35 & $3[1.4 \%]$ & $g / 1 / g / 1$ \\
\hline \multicolumn{9}{|l|}{ rpk1-7 allele: } \\
\hline$F N^{9-3} X P I N 1 G F P \_1$ & 237 & - & 13 & - & 18 & - & 3 [1.1\%] & GL1/GL1 \\
\hline$F N^{9-3}$ XPIN1GFP_2 & 130 & - & 6 & - & 12 & - & 2 [1.3\%] & GL1/GL1 \\
\hline$F N^{9-3} X P I N 1 G F P \_3$ & 171 & - & 4 & - & 9 & - & 1 [0.5 \%] & GL1/GL1 \\
\hline \multicolumn{9}{|l|}{ rpk1-6 allele: } \\
\hline N2995XPIN1GFP_1 & 71 & - & 14 & - & 15 & - & 1 [1 \%] & GL1/GL1 \\
\hline N2995XPIN1GFP_2 & 314 & - & 18 & - & 32 & - & 0 [0 \%] & GL1/GL1 \\
\hline N2995XPIN1GFP_3 & 223 & - & 32 & - & 69 & - & $11[3.3 \%]$ & GL1/GL1 \\
\hline
\end{tabular}

${ }^{a}$ presence(+) or absence (-) of trichomes indicated

b approx. \% of all seedlings

defects (Fig. 2f, Additional file 1: Figure S1). A search in rpk1-6 for a similar ectopic outgrowth revealed not more than one case among 737 seedlings (Fig. $2 \mathrm{~g}$ ) showing that this special structure is significantly rare. In order to assess the frequency of eSMs systematically, we grew large numbers $(>10.000)$ of $r p k 1-7$ seedlings in another genetic background (Table 2). The average amount of SAM-bearing and SAM-less monocots remained in the known range. However, the occurrence of eSMs was rare, had no predictable frequency in different pedigrees and was always linked to SAM-less monocots. Together, our observations showed that SAM-less monocot seedlings result from different mutations in RPK1. Therefore, in the following we concentrated on the analysis of the rpk1-7 alone.

\section{The eSM displays organizational similarities to wild-type SAMs}

A plant with an eSM was histologically compared with a "normal" monocot seedling (Fig 3). The latter developed a SAM at the base of the cotyledon, which harboured regular cell files belonging to epidermis, palisade, mesophyll and xylem/phloem tissue, very much like a SAM of a dicot seedling. Within all tissues, the cells showed regular cell size proportions and vacuolation. Stomata were found above small cavities and were well separated from each other by epidermal cells (Fig. 3a). The SAM was positioned at the base of the remaining cotyledon where it would be normally expected. Its organization consisted of a group of small densely stained cells, which laterally gave rise to leaf primordia (Fig. 3a). As seen from the vascular system, the origin of the cotyledon is lateral and not terminal.
The cotyledons of SAM-less monocots always displayed an adaxial/abaxial orientation as evidenced by well-developed laminae, their bending, the form of the continuous hypocotyl-cotyledon structure, lacking a real petiole, and the position of the developed SAM (Figs. 1 and 2). However, the tissues and cells were significantly disproportionate in shapes and sizes (Fig. 3b). Abnormal shapes of epidermal cells indicated abnormal (not anticlinal) divisions. Stomata were sometimes neighboured to each other (Fig. 3b, top inset) and inner cells could be extremely large $(>>100 \mu \mathrm{m}$ in length) and loosely attached to each other. In contrast, the regular (cellular) organization of the eSM was reminiscent of a wild-type SAM or the SAM in monocot siblings (compare Fig. 3a and $b$ ). A series of leaf primordia emerged from a cluster of small, plasma rich (densely stained) cells in the centre. The emerging eSM possibly caused a tension along the proximo-distal axis such that the cotyledon bent to form a buckle, which in turn produced a cavity beneath (Fig. 3b, compare with Fig. 2d).

Next, we addressed the question whether the loss of SAM in monocot rpk1-7 is the extreme of a gradual reduction of meristem size. Due to the abundance of plasma, shoot apical meristem cells of DAPI-stained seedlings show intensive fluorescence, which can be taken as an approximation to meristem size [25]. SAMs of seedling phenotypes of $r p k 1-7$ (i. e. dicots, monocots, seedlings with irregular e. g. fused cotyledons) were compared with wild-type SAMs (Col-0 ecotype) as well as with mutant clavata3 SAMs (Fig. 3c, d). The latter have been shown to be significantly larger than wildtype SAMs [26]. SAM-less monocot seedlings did not show densely stained SAM cell clusters (not shown). 


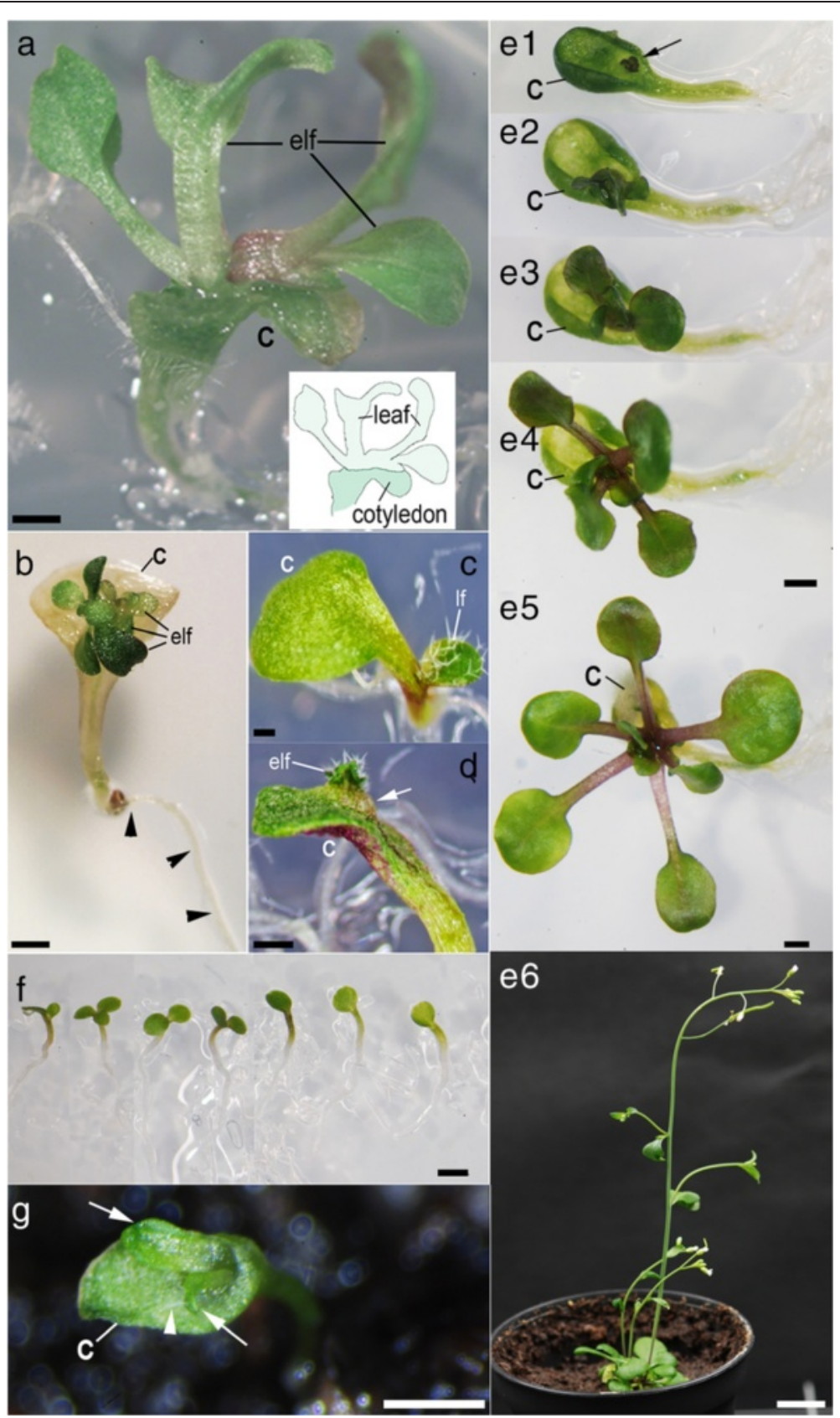

Fig. 2 SAM-less rpk1 seedlings produce ectopic shoot meristems on cotyledons. a Monocot rpk1-7 seedling with an adaxial ectopic shoot meristem (eSM) carrying several leaves (inset: scheme for clarification). b The same on a rpk 1-7 monocot seedling from long-term cultivation. The cotyledon has lost its greening. Arrowheads point to the root. c-d Monocot rpk1-7 seedlings in GL1 background with a normally positioned SAM c and with an ESM d respectively. Note the trichomes on the normal and ectopic primary leaves. A characteristic tissue outgrowth carries the eSM (arrow). e1-e5 Growth of an eSM (black arrow) on a cotyledon from a rpk1-7 seedling during the first two weeks. e6 The same after one month. f Progeny from the eSM rpk1-7 plant shown in e1-e6. g A rpk1-6 monocot seedling carrying two leaf outgrowths (arrows) on top of an abnormally thickened cotyledon. The arrowhead points to a trichome. Cotyledons (c), normal (If) and ectopic leaves (elf) are indicated. Scale bars: $1 \mathrm{~mm}$ except in $\mathbf{e} 6 \mathrm{e} 6: 1 \mathrm{~cm}$

The distribution of SAM sizes of rpk1-7 seedlings significantly overlapped with the sizes of wild-type SAMs. In contrast, the control clavata 3 mutant exhibited significantly larger SAMs (Fig. 3c, d). We conclude that the representatives of the different $r p k 1-7$ cotyledon variants are not members of a continuum of gradual decrease of SAM size. This suggests that the SAM-less monocot phenotype results from the incapability to reach a threshold required to establish a SAM (e. g. a critical amount or activity of coordinated SAM gene expression). 
Table 2 Frequency of ectopic meristems (eSMs)

\begin{tabular}{|c|c|c|c|c|c|}
\hline Line $^{a}$ & Dicots \& others ${ }^{b}$ & Monocots + SAM [\%] $^{c}$ & Monocots -SAM $[\%]^{c}$ & Monocots + eSM [\%] $^{\mathrm{c}}$ & Monocots (+SAM, -SAM, +eSM) [\%] \\
\hline rpk1-7 X KNAT2:GUS A & 1246 & $52[4]$ & $12[0.9]$ & $0[0]$ & 4.9 \\
\hline rpk1-7 X KNAT2:GUS B & 1902 & $165[7.7]$ & $62[3]$ & $1\left[4.5 \times 10^{-4}\right]$ & 10.7 \\
\hline rpk1-7 X KNAT2:GUS C & 1995 & $187[8.3]$ & $62[2.8]$ & $1\left[4.4 \times 10^{-4}\right]$ & 11.1 \\
\hline rpk1-7 X KNAT2:GUS D & 421 & $49[10.1]$ & $12[2.7]$ & $1\left[2.0 \times 10^{-3}\right]$ & 12.8 \\
\hline rpk1-7 X KNAT2:GUS E & 332 & 50 [12.9] & $5[1.5]$ & $1\left[2.5 \times 10^{-3}\right]$ & 14.4 \\
\hline rpk1-7 X KNAT2:GUS F & 3202 & $262[7.4]$ & $78[2.3]$ & $2\left[5.6 \times 10^{-4}\right]$ & 9.7 \\
\hline
\end{tabular}

${ }^{a}$ Outcrosses to marker line KNAT2p:GUS, repeatedly selfed and with g/1/g/1 and non-KNAT2p:GUS background

${ }^{b}$ Only monocots vs. others were considered, seedlings with irregular cotyledons, e. g. unequally sized (= anisocots), were not separately counted

'Percentage of all seedlings counted

${ }^{d}$ In three randomly selected batches tested, between $15-66 \%$ of initial -SAM seedlings developed a late SAM

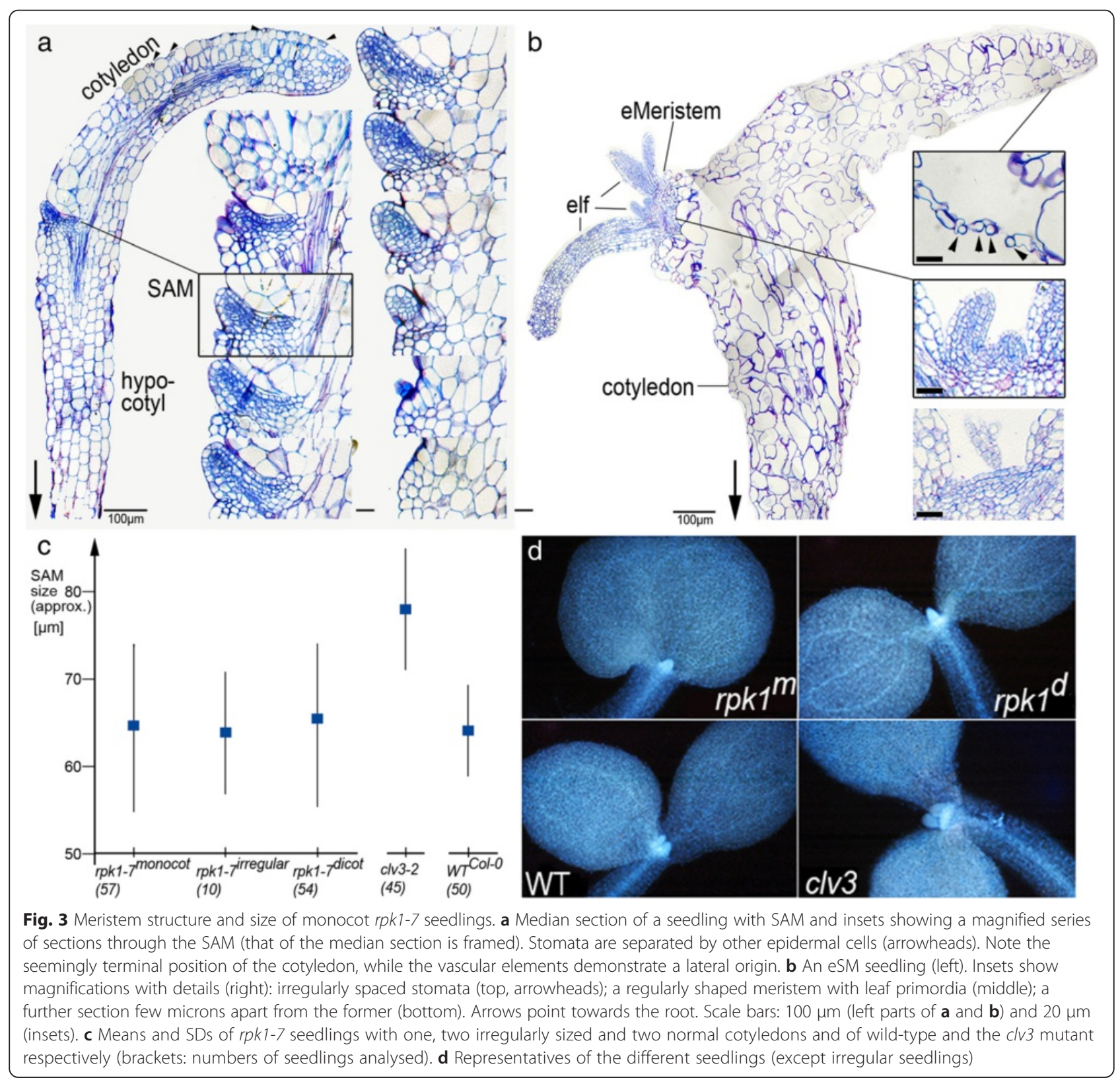


Cotyledons of SAM-less monocot rpk1-7 seedlings display SAM-specific gene expression

Next we analysed expression of SAM-specific genes such as WUS, STM, KNAT1 and KNAT2 (Fig. 4a) by semiquantitative RT-PCR (see Methods). In this and other experiments care was taken that SAM-less seedlings were in fact devoid of a recognizable (late) SAM and that experiments with separated cotyledon tissue were not contaminated with hypocotyl and root tissue (see Methods). The cotyledon and leaf specific $A S 1$ [27, 28] was included as control (in addition to $A C T 2$ ). In one experiment, two seedlings of the SAM-less and two of the SAM-bearing group were separately analysed (including those shown in Fig. 1a to 1c). SAM-less seedlings expressed three of the four SAM-specific genes together with $A S 1$, which was strongly expressed (Fig. 4a). While WUS was not found in these SAM-less seedlings, STM, KNAT1 and KNAT2 appeared to be aberrantly expressed in comparison to monocot seedlings with SAMs (Fig. 4a). The aliquots of both AS1 and $A C T 2$ displayed significantly stronger expression since these genes have an overall expression in the cotyledon and the rest of the seedling respectively. Testing STM and AS1 (and AS2, not shown) in pools of cotyledons separated from the rest of the body, showed STM expression in cotyledons of SAM-less seedlings but not in those of controls (Fig. 4b). In addition, STM expression was also found in the rest of SAM-less monocots and as expected in the two controls (Fig. 4b). All bands had the expected sizes (as derived from the known transcripts). Additionally, representative bands were sequence verified. The expression of STM in both groups of monocot seedlings was comparable. A similar result was obtained using material of single seedlings (Additional file 1: Figure S2).

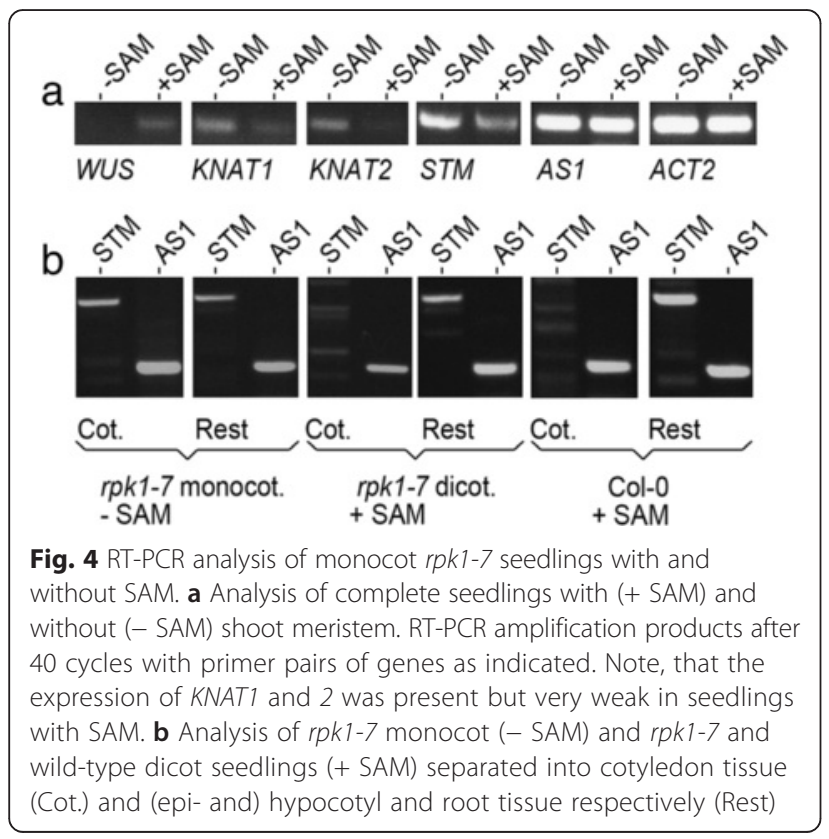

In situ hybridization analysis of late monocot $r p k$ 1-7 embryos detects a rare ectopic STM expression

We monitored the expression of SAM-specific (STM, $C L V 3)$ and cotyledon-specific (PID, ENP) genes, which starts at very early embryo stages. However, in contrast to our former study [22] we concentrated on late embryo stages for two reasons. First, in late embryogenesis, PID and ENP show an additional expression in the SAM (e. g. [5]). Second, we wanted to increase the probability to find the expectedly rare ectopic expression of one of these genes in the monocot embryos, which have themselves a rare penetrance.

Late monocot $r p k 1$ embryos displayed a "banana"-like appearance with a more or less recognizable notch harbouring the presumptive SAM region. As expected, we mostly detected correct expression patterns. STM showed a larger while $C L V 3$ exhibited a small expression domain as known (Fig. 5a-e6, Additional file 1: Figures S3 and S4 for comparison). Similarly, ENP and PID showed normal late expression in cotyledons and the SAM (Fig. 5f, g1-g4; Additional file 1: Figures S5 and S6 for comparison). Although any of these probes could have potentially detected an abnormal expression pattern, we found only one among 30 monocots (out of 328 rpk1-7 torpedo embryos). Considering the $10 \%$ frequency of SAM-less seedlings among monocot rpk1-7 seedlings, this is in the same range. Surprisingly, in the identified monocot embryo the hybridization with the STM probe extended almost along the complete embryonic hypocotyl but not into the cotyledon tissue, with the strongest concentration being at the normal SAM position (Fig. 5b1-b5; stippled line in B2 and B3). The size of the domain expressing STM in this specimen clearly exceeded $15-20 \mu \mathrm{m}$ in apical-basal axis, which is the size displayed in dicot and monocot SAM-bearing rpk1-7 torpedo embryos (Fig. 5a, d1-d6, e1-e6; brackets). This result coincides with one of the subsequently observed KNAT2p:GUS expression pattern variants in SAMless monocot rpk1-7 seedlings (see below).

\section{The SAM-specific KNAT2p-GUS activity is variable and abnormally distributed in SAM-less rpk1-7 monocot seedlings}

In order to obtain a larger number of specimen with informative ectopic expression patterns of a SAMrelated gene, we analysed Arabidopsis seedlings carrying a KNAT2p:GUS reporter [29]. KNAT2 is a STMdependent transcription factor whose expression is localised in the SAM [30] (Fig. 6a). The monocot pedigree of a rpk1-7 X KNAT2p:GUS cross contained normal dicot, SAM-bearing monocot and SAM-less monocot seedlings. The former two exhibited GUS stain as expected at the apex next to the base of the cotyledon(s) (Fig. 6a, b). The SAM-less monocots displayed a spectrum of variants with respect to KNAT2 


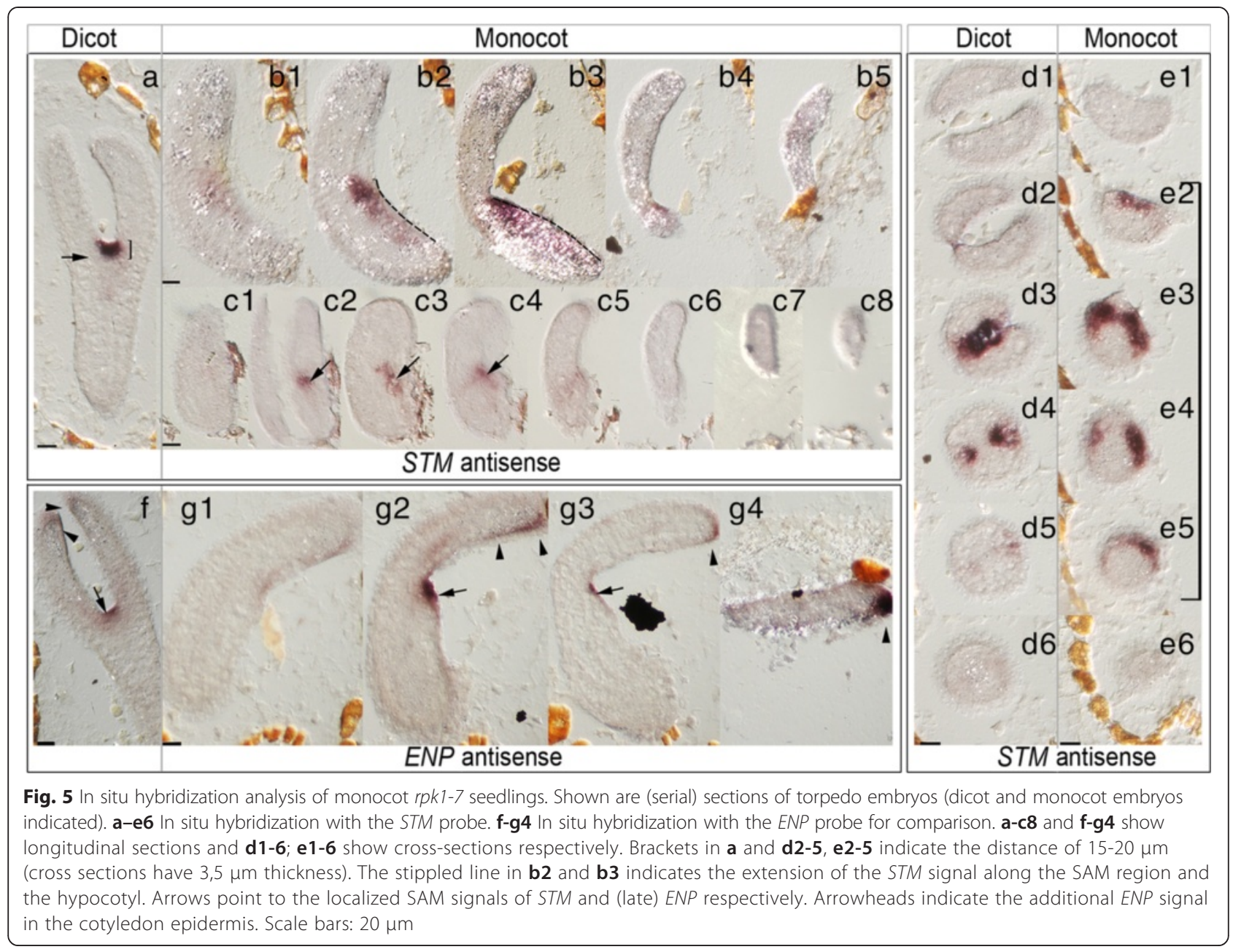

expression. Many seedlings showed very weak (Fig. 6c) to more intensive GUS expression in the central (vascular) tissue in the fused hypocotyl-cotyledon structure. This could extend either in direction towards the cotyledon tip or towards the root tip (Fig. 6d-h). The variability was further increased by some seedlings, which displayed smaller or larger patches of GUS staining in the cotyledon lamina (Fig. 6f-h). Monocot seedlings generating an eSM showed a strong GUS staining in the cotyledon (Fig. 6j). The variable KNAT2 expression in the cotyledon coincided with the results of the foregoing experiments. Thus, all expression data together suggest that SAM-less seedlings display an aberrant SAM gene expression pattern causing the generation of an eSM to be a rare event because it requires the concerted and precise coordination of several SAM genes.

\section{Discussion}

The timely and spatially stochastic alteration of cell division and PIN1 polarity in the embryo epidermis of rpk1 mutants causes a variable development of the cotyledon primordia, in particular the complete loss of one cotyledon indicating an early developmental accident during globular embryo stages [22]. Later we detected that among monocots of different rpk1 alleles the loss of the SAM had a low but consistent frequency and seemed to occur together with the generation of a continuous hypocotylcotyledon organ lacking a discernable epicotyl region. In this study we have systematically analysed this particular phenotype. Since the SAM-less phenotype is not a specialty of a single allele, we have focussed on $r p k 1-7$ when analysing the cellular morphology and gene expression patterns.

\section{SAM-less rpk1 seedlings lack a recognizable organ separation and display a compromised cell differentiation when developing eSMs}

The apex in Arabidopsis is formed through antagonistic activities of SAM-specific versus cotyledon/leaf specific genes [31]. Essentially, in the apex STM activates KNAT1/ $B P$ and KNAT2 (and KNAT6) directly or indirectly through repression of $A S 1$ and $A S 2$ [32, 33]. Conversely, a complex of the proteins AS1 (a MYB protein) and AS2 (a LOB 


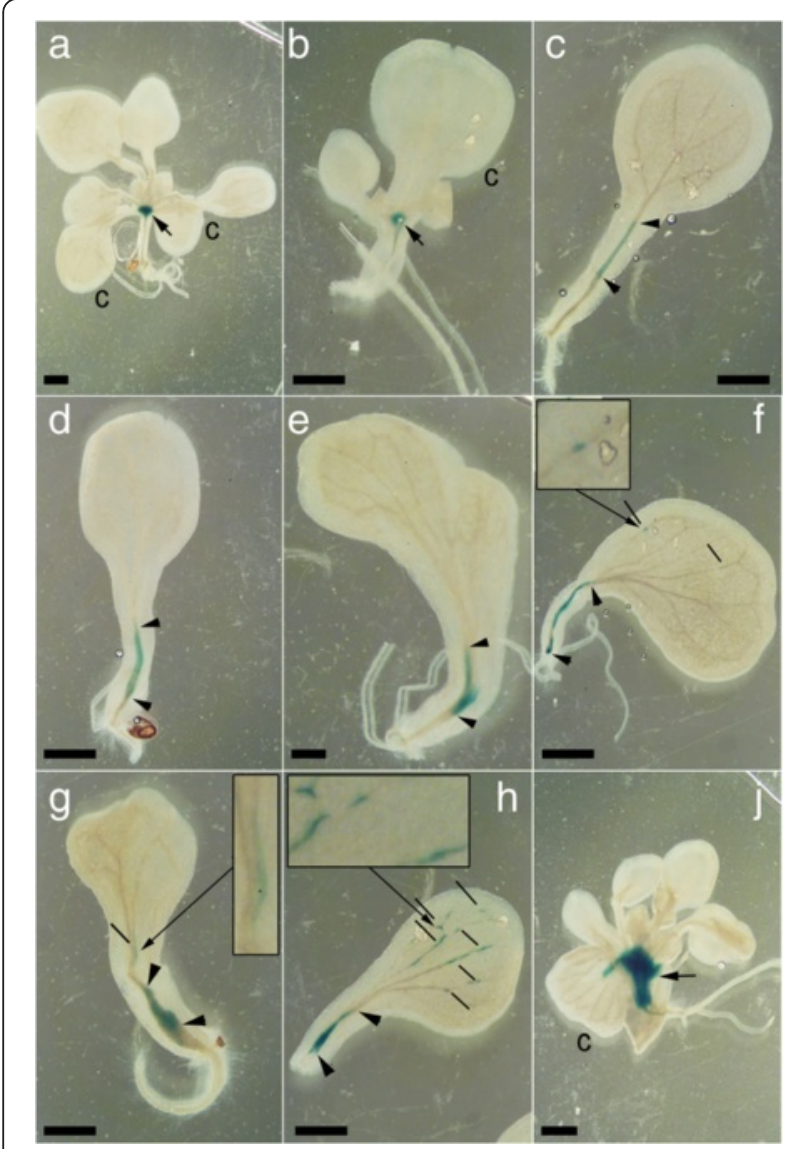

Fig. 6 Analysis of KNAT2p:GUS reporter construct in rpk1-7 background. Shown are wild-type $\mathbf{a}$ and monocot $r p k 1-7 \mathbf{b}$ with GUS stain in the SAM (arrow), SAM-less monocot rpk1-7 seedlings c-j with weak GUS expression (c), with variably extended GUS expression in the presumptive SAM position (d-h; arrowheads) and the cotyledon (f-h; short lines) and with an ESM in the cotyledon $\mathbf{j}$ Insets show details as magnifications. C: marks cotyledon in a-c and $\mathbf{j}$. Scale bars: $1 \mathrm{~mm}$

domain protein), which recruits chromatin-remodeling factors, excludes the activity of SAM specific class I KNOX genes, in particular KNAT1/BP and KNAT2 in leaf and cotyledon tissue [27, 28, 34, 35]. Thus, with the exception of plants, which have exploited the reactivation of SAMrelated genes in order to generate compound leaves [36], SAM gene activities are excluded from leaf tissue.

In cotyledon tissue of SAM-less rpk1-7 seedlings, we detected ectopic expression of the SAM-related STM, KNAT1 and KNAT2 genes together with cotyledon specific expression of AS1. This means that, antagonistic gene activities were detected within close neighbourhood in the same tissue and likely compromised cotyledon organization by generating tissues and cells with altered position, size and shape as evidenced from histological analysis. Similar profound changes in cell morphology have been observed in leaf tissue ectopically expressing single SAM specific genes (e. g. [37]). In accordance with the defect in PIN1 polarity, the disturbed vascular tissue pattern pointed to an auxin defect. Interestingly, eSMs generated rosettes with irregular phyllotactic patterns. In this context it is worth mentioning, that a balanced homeostasis of auxin and cytokinin impact on shoot development and phyllotaxis [38-40]. The development of a fused hypocotyl-cotyledon organ, at the expense of a petiole connecting hypocotyl and cotyledon, indicated severe perturbations of normal cell differentiation. In spite of these cellular disruptions, the morphology of this fused hypocotyl-cotyledon organ clearly retained the wildtype ab- and adaxial polarity in both rpk1-6 and rpk1-7 SAM-less monocots. No radialisation as reported for mutants of adaxial vs. abaxial identity genes was observed [41].

\section{SAM loss and eSM gain in monocot rpk1-7 seedlings is likely due to timely and spatially non co-ordinated expression of SAM specific genes}

Previous studies showed that, although ectopic (over-) expression of (single) KNOX genes could lead to ectopic SAMs, their stabilization required the balanced and concerted activity of stem cell identity and other SAM genes $[30,37,42,43]$. Our study shows that this is a main problem in SAM-less rpk1-7 mutants since the analyzed genes often exhibited a non-coordinated and unbalanced activity. For instance, in one case WUS was not expressed in cotyledons of SAM-less monocots while STM, KNAT1 and KNAT2 were. The latter also seemed to be even more strongly expressed in the mutant than in the wild-type. Since WUS expression is required for SAM generation on first place [44], this explains why these seedlings lacked a shoot meristem in spite of expressing other SAM related genes. Additionally, we detected inconsistencies of expression with respect to space and timing. Seedlings with late SAMs indicated a time-delayed co-ordination. This was also corroborated by SAM-less seedlings, which revealed ectopic KNAT2 p:GUS signals while others were almost devoid of this activity. The former also showed a spatial defect since GUS staining could occur in quite different positions and with variable extension. These observations explain why eSMs are rare and have no predictable frequency. They only develop by coincidence when all required SAM related genes are active in a concerted fashion and surpass critical values. Similarly, SAMs in "normal" monocot seedlings overlapped in size with wild-type SAMs instead of showing a continuum of gradually decreasing sizes until reaching a SAM-less seedling.

\section{SAM-less rpk1 seedlings are caused rather by lack of positional information than suppression of SAM specific gene activity}

The rpk1 phenotypes raise the question whether RPK1 induces the initiation of cotyledon primordia and the SAM through direct control of the corresponding genes. Both possibilities can be excluded. First, in case of the 
former, $r p k 1$ mutants should provide seedlings precisely lacking both cotyledons like pid enp double mutants [4]. This has not been the case among all analysed rpk1 homozygous progenies ( $>>10.000)$. Interestingly, monocot rpk1 embryos develop only one primordium but establish both cotyledon anlagen [22]. This is compatible with former fate-mapping experiments, which suggest a sequential generation of cotyledons [45]. Second, our data also exclude the possibility that RPK1 directly controls SAM gene expression and development because SAM-less rpk1-7 seedlings retain the capacity to express a variety of SAM-specific genes and even to generate eSMs. This corroborates the notion that cotyledons and SAM are largely developmentally independent.

However, what then causes ectopic SAM gene expression and eSM development? Homozygous rpk1 mutants differ from previous examples where ectopic shoot meristems were induced in transgenic and complex dominant mutation backgrounds respectively [30, 37, 42, 43, 46]. In contrast, rpk1 mutants represent a loss-of-function state and form late SAMs at correct positions or eSMs ectopically on top of cotyledons. The rpk1-7 ectopic shoots, although larger, are reminiscent of epiphyllous inflorescences on foliage leaves in fil-5 yab3-1 mutants [47] and of ectopic leaf buds in as1 mutants [27]. However, none of these genes is mutated in rpk1 plants. The only link to ectopic SAM gene expression (and eSMs) in these mutants is the altered hypocotyl-cotyledon fusion morphology. The probability that eSMs occurred exclusively in morphologically altered SAM-less monocots (6 in 10000; Table 2) just by chance is extremely low $\left(\leq 10^{-12}\right)$. This leads us to a model, which integrates the primary defects of rpk 1 mutants, i. e. disturbance of epidermal PIN1 polarity and cell division, and their phenotypes (Fig. 7). In fact, disturbance of PIN1 polarity and auxin homeostasis respectively have been demonstrated to affect initiation of shoot regeneration [39, 48, 49]. Our model takes into account, that due to functional redundancy these defects stochastically scatter along the complete embryo development (Fig. 7). The earlier the rpk1 defects manifest the more severe are the consequences. The extreme is a fused hypocotyl-cotyledon morphology with the loss of the SAM, which is one of the earliest cell commitments in the embryo (Fig. 7). Apparently, the continuous hypocotyl-cotyledon morphology is accompanied by a loss of positional information because post-embryonically a shoot meristem can form at different positions (late SAMs, eSMs). This circumstance is also reflected in variable ectopic SAM gene expression patterns in those SAM-less monocots, which fail to form a shoot meristem (Fig. 7).

\section{Conclusions}

This study shows that RPK1 does not primarily control SAM genes, even the extreme rpk1-7 phenotype retains the capacity to resume shoot meristem development $(\mathrm{eSM})$ and to generate a fully functional plant. However, RPK1 does well impact through its primary defects on the generation of shoots and (cotyledon) organs demonstrating a significant extent of morphological plasticity. This plasticity leads to intriguing similarities with extant angiosperms in particular real monocots and monocotyledonous dicots of the genera Monophyllea [50] and Streptocarpus [51] respectively. RPK1 mutants are also instructive in a way that sheds light on an aspect that has received less attention. This is the penetrance problem. In contrast to full penetrance of cotyledon-loss in pid

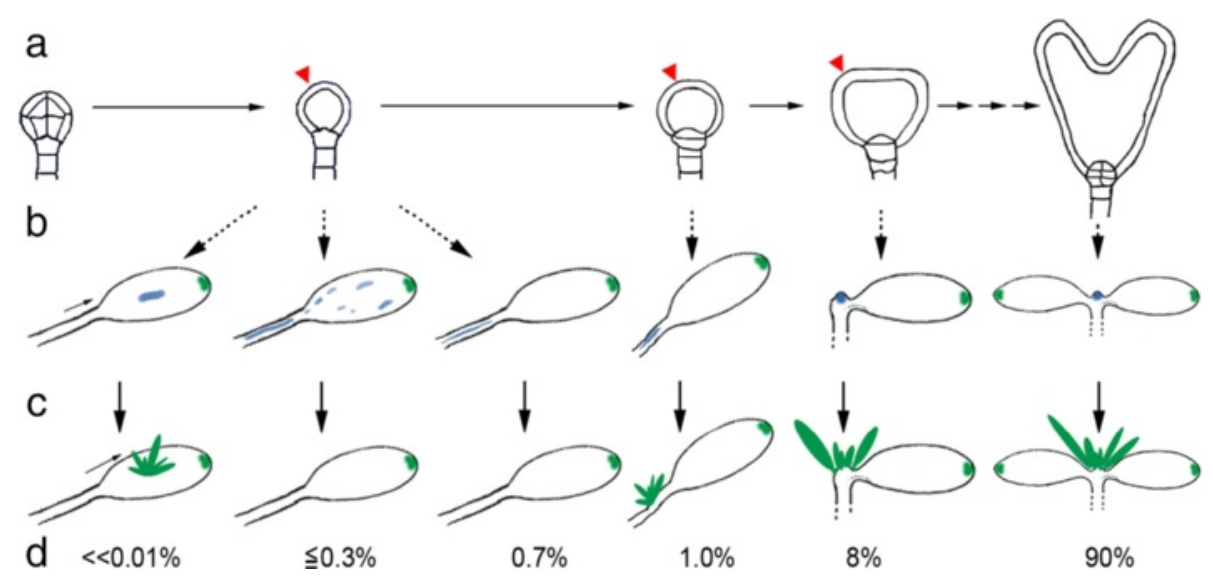

Fig. 7 Model explaining early rpk1-7 defects. a The failure to achieve sufficient RPK1 function (red arrowheads) by redundant genes in the rpk1-7 mutant is stochastic with respect to time and space. Early alterations have more severe effects than late ones on SAM- vs. cotyledon organizing cell groups. b Given are possible expression patterns (blue) of KNAT2p:GUS as an example for a SAM-related gene. c The realization and maintenance of a shoot meristem depends on the precisely localized and concerted expression of all required SAM genes. d Shown are the frequencies of mono- and dicots with and without SAMs/eSMs based mainly on rpk1-7 data (for details see text and Methods). Green spots symbolize auxin maxima. Note that repeated PIN1 polarity and cell division disturbance can cause additional maxima and lobed cotyledons (see [22]) 
enp [4], known single or combined mutations in Arabidopsis, do not stably produce $100 \%$ monocots [22, 23]. This phenomenon has been previously addressed by studying modifier genes of cotyledon number in Antirrhinum majus (e. g. [52]). More recently, an association study using $A$. thaliana ecotypes has identified $R P K 1$ as an essential (but not the only) gene for shoot organ regeneration [53]. Thus, the rpk1 monocot phenotype furthers our understanding of angiosperm development in two ways. First, it points to the organizational and genetic peculiarities required to generate a monocotyledonous plant from a dicot. Second, it shows, that it might be promising to search for those genes whose functions have to be altered in concert to obtain full penetrance of monocotyly.

\section{Methods}

Plant strains and growth conditions

The Col-0 ecotype was used as wild-type reference. The strong rpk1-7 allele originated from the selfing of a fast neutron mutagenized seed of $\mathrm{Col} / g l-1$ background and represents an inversion mutation [22]. Monocot rpk1-6 and rpk1-7 seedlings were analysed in the original line and in different backgrounds resulting after crossing with different (reporter) lines. In $r p k 1-7$, the $g l-1$ background results in loss of trichomes characteristic for post-embryonic leaves. Therefore, $r p k 1-7$ was crossed to GL-1 background (harbouring the PIN1p:PIN1::GFP reporter). The KNAT2p::GUS reporter [29] was crossed with $r p k 1-7$ in order to detect ectopic SAM gene-related expression patterns. Segregating $g l 1 / g l 1$ pedigree of this cross lacking the KNAT2p::GUS reporter was used for assessing eSM frequency. The rpk1-6 allele is a T-DNA insertion $357 \mathrm{bp}$ from the ATG in the ecotype WS-2 obtained from NASC (Nottingham Arabidopsis Stock Center; for further details see [22]). This allele was either analysed as original line or as line harbouring the PIN1p:PIN1::GFP reporter. Growing of seedlings on soil was essentially as described [22]. Seeds were surface sterilized in calcium hypochloride (ca. $5 \%, 15 \mathrm{~min}$ ) and then washed $3 \mathrm{X}$ in $\mathrm{H}_{2} \mathrm{O}$. Sterile culturing of SAM-less monocot seedlings was initially performed on 0.5X MS in petri dishes and later in magenta boxes respectively under continuous light and $21^{\circ} \mathrm{C}$.

\section{Microscopy}

Semi-thin sections and whole mount analysis of embryos and seedlings were carried out as previously described $[4,12,54]$. Photographs were taken using a ZEISS Axiophot1 microscope equipped with a Digital Nikon camera (F5SLR) and corresponding software (Nikon Camera Control Pro). Epifluorescence microscopy on the same Axiophot used a HBO50 UV/Light-source with a DAPI filter system (Zeiss filter set 01, BP365/FT395/LP397).

\section{GUS-Staining}

Staining of seedlings carrying the GUS reporter construct was carried out after fixation by vacuum infiltrating a solution of $\mathrm{NaH}_{2} \mathrm{PO}_{4}(\mathrm{pH}$ 7.0) and 1 \% Formaldehyde for $10 \mathrm{~min}$ in an Eppendorf tube. After placing the tube for $20 \mathrm{~min}$ on ice, the fixative was washed off with $50 \mathrm{mM}$ $\mathrm{NaH}_{2} \mathrm{PO}_{4}$ ( $\mathrm{pH}$ 7.0) and staining was performed as previously described [55]. SAM-less monocot seedlings showing GUS staining were taken to estimate the proportion of SAM-less monocots with ectopic expression in the cotyledon vs. those with expression exclusively in the hypocotyl.

\section{RT-PCR and PCR}

Plant DNA was isolated following conventional protocols. RNA isolation, reverse transcription and PCR were performed according to the supplier's instructions using a NucleoSpin ${ }^{\circ}$ RNA Plant (Macherey-Nagel) or PolyATractSystem IV kit (Promega) respectively. Reverse transcription of total RNA with a TaqMan ${ }^{\odot}$ kit (Applied Biosystems, Roche) included the following steps: $20 \mathrm{~min} 25{ }^{\circ} \mathrm{C}$ followed by $45 \mathrm{~min} 48{ }^{\circ} \mathrm{C}$ and stopped with $5 \mathrm{~min}$ at $95{ }^{\circ} \mathrm{C}$. RT-PCR analysis was semi-quantitative; i. e. for probes to be compared the same amount of RNA material was used in the RT reaction and/or amounts of PCR products loaded were adjusted with respect to the $A C T 2$ reactions. Fig. 4a, Fig. 4b and Additional file 1: Figure S2 show independent experiments because three different seedling batches were used. Especial care was taken using isolated cotyledon tissue by locating the section at safe distance to the hypocotyl-cotyledon fusion region.

The following forward and reverse primer pairs were used (gene and fragment size in parentheses):

5'-GCCCATCATGACATCACATC-3' and 5' - CTTT AAGCTCTCTATCCTCAGCTTG-3' (STM; 701 bp frag ment); 5'-GGCACCGAGCTTGGGCAGAC-3' and 5' GAGACGGTTCAGGGGCGGTC-3 (AS1; 322 bp); 5' TCAGAAGAAGAGATTCAAC-3' and 5' -AGGGCGAA CTTCCGATTGG-3' (WUS; 562 bp); 5'-CACCGTCT GTCTCTGCCTCCTCTA-3' and 5' -ATTCCGCCAACG CTACCTTCTCT-3' (KNAT1; 534 bp); GGAGCTGATC CTGAGCTTGATG-3' and 5'-CACCAATCGAGCAAC GCTTGTC-3 (KNAT2; 380 bp); 5'-TTGTTCCAGCCC TCGTTTGT-3' and 5'-CCTGGACCTGCCTCATCATA CT-3' (ACT2; $323 \mathrm{bp})$. PCR cycles were: $3 \mathrm{~min} 93{ }^{\circ} \mathrm{C}$, 40X (45 s $93{ }^{\circ} \mathrm{C}, 60 \mathrm{~s} 60{ }^{\circ} \mathrm{C}$ and $\left.60 \mathrm{~s} 72{ }^{\circ} \mathrm{C}\right), 3 \mathrm{~min} 72{ }^{\circ} \mathrm{C}$, $3 \min 4^{\circ} \mathrm{C}$.

In order to assess correct gene identities some RT-PCR products were sequenced through EUROFINS/MWG services.

\section{In situ hybridisation analyses}

In situ hybridization, assessment of anti- and sense probes and wild-type expression patterns were as previously reported and had been previously confirmed 
respectively [4, 22]. In contrast to the study of Luichtl et al. [22], we focused on embryos from early torpedo stage onwards.

\section{Additional file}

Additional file 1: Figure S1. Progeny of an eSM of monocot rpk1-7 plants. Figure S2: RT-PCR analysis of single rpk1-7 monocot seedlings. Figure S3: In situ hybridization of dicot rpk1-7 embryos with a STM probe. Figure S4: In situ hybridization of dicot and monocot rpk1-7 embryos with a CLV3 probe. Figure S5: In situ hybridization of dicot rpk1-7 embryos with an ENP probe. Figure S6: In situ hybridization of dicot and monocot rpk1-7 embryos with a PID probe.

\section{Abbreviations}

ACT2: ACTIN2; AS1: ASSYMMETRIC LEAVES1; AS2: ASSYMMETRIC LEAVES2; BP: BREVI PEDICELLUS; CLV3: CLAVATA3; clv3: clavata3; Col-0: Columbia-0; ENP: ENHANCER OF PINOID; enp: enhancer of pinoid; eSM: ectopic Shoot Meristem; gl1: glabra1; GUS: beta-Glucuronidase; KNAT1: KNOTTED1-LIKE ARABIDOPSIS THALIANA1; KNAT2: KNOTTED1-LIKE ARABIDOPSIS THALIANA2; LOB: Lateral Organ Boundary; MIPS: D-myo-inositol-3-phosphate synthase; MS: Murashige Skoog; NASC: Nottingham Arabidopsis Stock Center; NPH3: NON-PHOTOTROPIC HYPOCOTYL3; PID: PINOID; pid: pinoid; PIN1: PINFORMED1; RAM: Root Apical Meristem; RPK1: RECEPTOR-LIKE PROTEIN KINASE1; RPK2: RECEPTOR-LIKE PROTEIN KINASE2; SAM: Shoot Apical Meristem; sic: single cotyledon; STM: SHOOT MERISTEM-LESS; WS-2: Wassilewskija-2; WUS: WUSCHEL.

\section{Competing interests}

The authors declare that they have no competing interests.

\section{Authors' contributions}

BSF and ML performed mutant characterization and in situ analyses, XY, MM and OP participated in further molecular analyses and characterization of lines, RATR designed the project, participated in molecular, phenotyping and genetic work and wrote the paper. All authors read and approved the final manuscript.

\section{Acknowledgements}

We are indebted to F. Assaad for comments and critical reading of the manuscript and H. Miller-Mommerskamp and R. Radykewicz for help. Part of this work was supported by the DFG (Grant To134/8-1 to R.A.T.R.). We thank Alfons Gierl for his support of our work and NASC for plant lines. The authors declare no conflict of interest.

\section{Author details}

'Lehrstuhl für Genetik, Technische Universität München,

Wissenschaftszentrum Weihenstephan, Emil-Ramann-Str. 8, D-85354 Freising, Germany. ${ }^{2}$ Lehrstuhl für Pflanzenzüchtung, Technische Universität München, Wissenschaftszentrum Weihenstephan, Liesel-Beckmann-Str. 2, D-85354 Freising, Germany.

\section{Received: 18 March 2015 Accepted: 16 June 2015}

Published online: 07 July 2015

\section{References}

1. Jürgens $G$, Torres Ruiz RA, Berleth T. Embryonic pattern formation in flowering plants. Annu Rev Genet. 1994;28:351-71.

2. Long JA, Moan El, Medford J, Barton MK. A member of the KNOTTED class of homeodomain proteins encoded by the STM gene of Arabidopsis. Nature. 1996;379:66-9.

3. Mayer KFX, Schoof H, Haecker A, Lenhard M, Jürgens G, Laux T. Role of WUSCHEL in Regulating Stem Cell Fate in the Arabidopsis Shoot Meristem. Cell. 1998:95:805-15.

4. Treml BS, Winderl S, Radykewicz R, Herz M, Schweizer G, Hutzler P, et al. The gene ENHANCER OF PINOID controls cotyledon development in the Arabidopsis embryo. Development. 2005;132:4063-74.
5. Furutani M, Kajiwara T, Kato T, Treml BS, Stockum C, Torres-Ruiz RA, et al. The gene MACCHI-BOU4/ENHANCER OF PINOID encodes a NPH3-like protein and reveals similarities between organogenesis and phototropism on the molecular level. Development. 2007:134:3849-59.

6. Cronquist A. The Evolution and Classification of Flowering Plants. 2nd ed. Bronx, New York: The New York Botanical Garden; 1988

7. Crane PR, Friis EM, Pedersen KR. The origin and early diversification of angiosperms. Nature. 1995;374:27-33.

8. Angiosperm Phylogeny Group III. An update of the Angiosperm Phylogeny Group classification for the orders and families of flowering plants: APG III. Bot J Linnean Soc. 2009;161:105-21.

9. Chaudhury AM, Letham S, Dennis ES. amp1 - a mutant with high cytokinin levels and altered embryonic pattern, faster vegetative growth, constitutive photomorphogenesis and precocious flowering. Plant J. 1993;4:907-16.

10. Vidaurre DP, Ploense S, Krogan NT, Berleth T. AMP1 and MP antagonistically regulate embryo and meristem development in Arabidopsis. Development. 2007:134:2561-7.

11. Chandler JW, Cole M, Flier A, Grewe B, Werr W. The AP2 transcription factors DORNRÖSCHEN and DORNRÖSCHEN-LIKE redundantly control Arabidopsis embryo patterning via interaction with PHAVOLUTA. Development. 2007:134:1653-62.

12. Torres Ruiz RA, Jürgens G. Mutations in the FASS gene uncouple pattern formation and morphogenesis in Arabidopsis development. Development. 1994;120:2967-78.

13. Benkova E, Michniewicz M, Sauer M, Teichmann T, Seifertova D, Jurgens G, et al. Local, efflux-dependent auxin gradients as a common module for plant organ formation. Cell. 2003;115:591-602.

14. Friml J, Yang X, Michniewicz M, Weijers D, Quint A, Tietz O, et al. A PINOIDdependent binary switch in apical-basal PIN polar targeting directs auxin efflux. Science. 2004;306:862-5.

15. Bennett SRM, Alvarez J, Bossinger G, Smyth DR. Morphogenesis in pinoid mutants of Arabidopsis thaliana. Plant J. 1995:8:505-20.

16. Luo Y, Qin G, Zhang J, Liang Y, Song Y, Zhao M, et al. D-myo-Inositol-3Phosphate affects Phosphatidylinositol-Mediated endomembrane function in Arabidopsis and is essential for auxin-regulated embryogenesis. Plant Cell. 2011:23:1352-72

17. Cheng Y, Qin G, Dai X, Zhao Y. NPY genes and AGC kinases define two key steps in auxin-mediatedf organogenesis in Arabidopsis. Proc Nat Acad Science USA. 2008;105:21017-22.

18. Dhonukshe P, Huang F, Galvan-Ampudia CS, Mähönen AP, Kleine-Vehn J, Quint A, et al. Plasma membrane-bound AGC3 kinases phosphorylate PIN auxin carriers at TPRXS(N/S) motifs to direct apical PIN recycling. Development. 2010;137:3245-55

19. Won $C$, Shen $X$, Mashiguchi $K$, Zheng $Z$, Dai $X$, Cheng $Y$, et al. Conversion of tryptophan to indole-3-acetic acid by TRYPTOPHAN AMINOTRANSFERASES OF ARABIDOPSIS and YUCCAs in Arabidopsis. Proc Nat Acad Science USA. 2011;108:18518-23.

20. Liu C-M, Johnson S, Di Gregorio S, Wang TL. Single cotyledon (sic) Mutants of Pea and Their Significance in Understanding Plant Embryo Development. Dev Genet. 1999;25:11-22.

21. Nodine MD, Yadegari R, Tax F. RPK1 and TOAD2 are two receptor-like kinases redundantly required for Arabidopsis embryonic pattern formation. Dev Cell. 2007;12:943-56.

22. Luichtl M, Fiesselmann BS, Matthes M, Yang X, Peis O, Brunner Ä, et al. Mutations in the Arabidopsis RPK1 gene uncouple cotyledon anlagen and primordia by modulating epidermal cell shape and polarity. Bio Open. 2013;2:1093-102.

23. Nodine MD, Tax F. Two receptor-like kinases required together for the establishment of Arabidopsis cotyledon primordia. Dev Biol. 2008;314:161-70.

24. Kinoshita A, Betsuyaku S, Osakabe Y, Mizuno S, Nagawa S, Stahl Y, et al. RPK2 is an essential receptor-like kinase that transmits the CLV3 signal in Arabidopsis. Development. 2010;137:3911-20.

25. Laux T, Mayer KFX, Berger J, Jürgens G. The WUSCHEL gene is required for shoot and floral meristem integrity in Arabidopsis. Development. 1996;122:87-96.

26. Clark SE, Running MP, Meyerowitz EM. CLAVATA3 is a specific regulator of shoot and floral meristem development affecting the same processes as CLAVATA1. Development. 1995;121:2057-67.

27. Byrne ME, Barley R, Curtis M, Arroyo JM, Dunham M, Hudson A, et al. Asymmetric leaves 1 mediates leaf patterning and stem cell function in Arabidopsis. Nature. 2000;408:967-71. 
28. Guo M, Thomas J, Collins G, Timmermans MCP. Direct repression of KNOX loci by the ASYMMETRIC LEAVES1 complex of Arabidopsis. Plant Cell. 2008;20:48-58

29. Laufs P, Dockx J, Kronenberger J, Traas J. MGOUN1 and MGOUN2: two genes required for primordium initiation at the shoot apical and floral meristems in Arabidopsis thaliana. Development. 1998;125:1253-60.

30. Gallois JL, Woodward C, Reddy GV, Sablowski R. Combined SHOOT MERISTEMLESS and WUSCHEL trigger ectopic organogenesis in Arabidopsis. Development. 2002;129:3207-17.

31. Hay A, Tsiantis M. A KNOX family TALE. Curr Op Plant Biol. 2009;12:593-8.

32. Scofield S, Murray JAH. KNOX gene function in plant stem cell niches. Plant Mol Biol. 2006:60:929-46.

33. Byrne ME, Simorowski J, Martienssen RA. ASYMMETRIC LEAVES1 reveals knox gene redundancy in Arabidopsis. Development. 2002;129:1957-65.

34. Semiarti E, Ueno Y, Tsukaya H, Iwakawa H, Machida C, Machida Y. The ASYMMETRIC LEAVES2 gene of Arabidopsis thaliana regulates formation of a symmetric lamina, establishment of venation and repression of meristem-related homeobox genes in leaves. Development. 2001;128:1771-83.

35. Li Z, Li B, Shen WH, Huang H, Dong A. TCP transcription factors interact with AS2 in the repression of class-I KNOX genes in Arabidopsis thaliana. Plant J. 2012;71:99-107

36. Blein T, Pulido A, Vialette-Guiraud A, Nikovics K, Morin H, Hay A, et al. A conserved molecular framework for compound leaf development. Science. 2008;322:1835-9.

37. Chuck G, Lincoln C, Hake S. KNAT1 induces lobed leaves with ectopic meristems when overexpressed in Arabidopsis. Plant Cell. 1996;8:1277-89.

38. Leibfried A, To JPC, Busch W, Stehling S, Kehle A, Demar M, et al. WUSCHEL controls meristem function by direct regulation of cytokinin-inducible response regulators. Nature. 2005;438:1172-5.

39. Cheng ZJ, Wang L, Sun W, Zhang Y, Zhou C, Su YH, et al. Pattern of auxin and cytokinin responses for shoot meristem induction results from the regulation of cytokinin biosynthesis by AUXIN RESPONSE FACTOR3. Plant Physiol. 2013;161:240-51.

40. Besnard F, Refahi Y, Morin V, Marteaux B, Brunoud G, Chambrier P, et al. Cytokinin signalling inhibitory fields provide robustness to phyllotaxis. Nature. 2014;505:417-21.

41. Emery JF, Floyd SK, Alvarez J, Eshed Y, Hawker NP, Izhaki A, et al. Radial Patterning of Arabidopsis Shoots by Class III HD-ZIP and KANADI Genes. Current Biology. 2003;13:1768-74.

42. Sinha NR, Williams RE, Hake S. Overexpression of the maize homeobox gene, KNOTTED-1, causes a switch from determinate to indeterminate cell fates. Genes Dev. 1993;7:787-95.

43. Brand U, Grünewald M, Hobe M, Simon R. Regulation of CLV3 Expression by two homeobox genes in Arabidopsis. Plant Phys. 2002;129:565-75.

44. Gaillochet C, Dau G, Lohmann JU. O Cell, Where Art Thou? The mechanisms of shoot meristem patterning. Curr Opin Plant Biol. 2015;23:91-7.

45. Woodrick R, Martin PR, Birman I, Pickett FB. The Arabidopsis embryonic shoot fate map. Development. 2000;127:813-20.

46. McConnell JR, Barton MK. Leaf polarity and meristem formation in Arabidopsis. Development. 1998;125:2935-42

47. Siegfried KR, Eshed Y, Baum SF, Otsuga D, Drews GN, Bowman JL. Members of the YABBY gene family specify abaxial cell fate in Arabidopsis. Development. 1999:126:4117-28.

48. Gordon SP, Heisler MG, Reddy GV, Ohno C, Das P, Meyerowitz EM. Pattern formation during de novo assembly of the Arabidopsis shoot meristem. Development. 2007;134:3539-48.

49. Atta R, Laurens L, Boucheron-Dubuisson E, Guivarc'h A, Carnero E, Giraudat-Pautot $V$, et al. Pluripotency of Arabidopsis xylem pericycle underlies shoot regeneration from root and hypocotyl explants grown in vitro. Plant J. 2009;57:626-44.

50. Tsukaya $H$. Determination of the unequal fate of cotyledons of a one-leaf plant, Monophyllaea. Development. 1997;124:1275-80.

51. Harrison J, Möller M, Langdale J, Cronk Q, Hudson A. The role of KNOX genes in the evolution of morphological novelty in Streptocarpus. Plant Cell. 2005;17:430-43.

52. Stubbe H. Über die Stabilisierung des sich variabel manifestierenden Merkmals "Polycotylie" von Antirrhinum majus L. Die Kulturpflanze. 1963;XI:250-63.

53. Motte H, Vercauteren A, Depuydt S, Landschoot S, Geelen D, Werbrouck S, et al. Combining linkage and association mapping identified RECEPTOR-LIKE PROTEIN KINASE1 as an essential Arabidopsis shoot regeneration gene. Proc Nat Acad Science USA. 2014;111:8305-10.
54. Haberer G, Erschadi S, Torres Ruiz RA. The Arabidopsis gene PEPINO/PASTICCINO2 is required for proliferation control of meristematic and non-meristematic cells and encodes a putative anti-phosphatase. Dev Genes Evol. 2002;212:542-50.

55. Jefferson RA, Kavanagh TA, Bevan MW. GUS fusions: beta-glucuronidase as a sensitive and versatile gene fusion marker in higher plants. EMBO J. 1987;6:3901-7.

\section{Submit your next manuscript to BioMed Central and take full advantage of:}

- Convenient online submission

- Thorough peer review

- No space constraints or color figure charges

- Immediate publication on acceptance

- Inclusion in PubMed, CAS, Scopus and Google Scholar

- Research which is freely available for redistribution 